\title{
Assessment of Peer Rejection and Externalizing Behavior Problems in Preschool Boys: A Short-Term Longitudinal Study
}

\author{
Sheryl L. Olson ${ }^{1,2}$ and Pearl L. Brodfeld ${ }^{1}$
}

We examined the longitudinal stability of measures of negative peer status and aggressive-disruptive behavior in preschool boys. Subjects were 53 white 4- to 5-year-old boys from low-income family backgrounds. Peer sociometric measures of rejection and behavioral deviance were assessed in the fall and spring of the preschool year. Complementary measures were also obtained from teachers at both assessment points. Half of the boys designated as rejected on the basis of peer nominations maintained this status at the end of the preschool year. Teachers and peers did not agree on their selections of socially rejected children, but had good agreement concerning the identification of children with externalizing-type behavior problems. Finally, teacher and peer classifications of aggressive-disruptive children were highly stable throughout the preschool year. These findings indicate that peer-rejected children can be identified at very young ages, and that preschoolers can be reliable informants about the social maladjustment of peers.

There is ample evidence that negative peer status in childhood is a risk factor for serious maladjustment in later life (see review by Parker \& Asher, 1987). In order to identify children most strongly in need of intervention, sensitive assessment techniques are essential. Among children who lack peer acceptance, an important distinction has been

Manuscript received in final form March 6, 1991.

We thank the Head Start children, parents and staff who participated, and Karen Lifgren for her help with data collection.

${ }^{1}$ Department of Psychology, University of Michigan, Ann Arbor, Michigan 48109.

${ }^{2}$ Address all correspondence to S. L. Olson, Department of Psychology, University of Michigan, 580 Union Drive, Ann Arbor, Michigan 48109. 
made between those who are neglected and those who are rejected by peers (Coie, Dodge, \& Coppotelli, 1982; Goldman, Corsini, \& deUrioste, 1980). Neglected children lack friends and tend to be ignored by their peers, but they are not necessarily disliked. By contrast, rejected children are actively disliked by peers, and tend to show relatively high rates of aggressive and disruptive behavior in peer group settings (Coie et al., 1982; Dodge, 1983). Furthermore, rejected children are more likely than others to retain their negative social status when they move into new peer groups (Coie \& Dodge, 1983; Newcomb \& Bukowski, 1983). Finally, rejected status is more stable over time than other status classifications (Asher \& Dodge, 1986).

It seems, therefore, that children who experience peer rejection tend to retain their negative status and fall into a pattern of social ostracism. These findings suggest that rejected children comprise a clear risk group and should be the focus of continued descriptive research and early intervention/prevention efforts. But at what age does rejection become firmly established? Although there has been a great deal of research with school-age children, much less is known about patterns of social rejection in younger children. Most particularly, we lack shortterm longitudinal research on negative peer status in preschoolers.

Accordingly, the main purpose of this study was to examine the stability of measures of social rejection in preschool children. Subjects were preschoolers who shared two characteristics that have been independently related to risk of externalizing behavior problems: male sex (Crowther, Bond, \& Rolf, 1981), and low-income family status (Rutter and Garmezy, 1983). This sample was selected with the expectation of identifying higher than average rates of externalizing-type behavior problems (aggression, impulsivity, disruptiveness), which have been linked to peer rejection in previous studies. The standard technique for identifying rejected children involves asking them to nominate a restricted set of most- and least-liked peers (e.g., McCandless \& Marshall, 1957, with preschool populations). Teachers were also asked to assign children to corresponding sociometric groups, so that peer and teacher designations of social rejection could be compared. Finally, because aggressive and disruptive behavior has been consistently related to peer rejection and is itself a risk factor for long-term social maladjustment (e.g., Loeber, 1982; Spivack, Marcus, \& Swift, 1986), peers and teachers were also asked to identify children who showed very high rates of these problems. 
Major research questions were as follows:

1. How stable are negative peer nominations and classifications of rejected status over the course of the preschool year? Although these classifications have moderately high stability in school-age populations (Asher \& Dodge, 1986), we questioned whether negative sociometric choices of preschool-age children would remain stable over a significant time period, given the young age of the respondents.

2. To what extent do teachers and peers agree on assignment of children to sociometrically rejected groups? To answer this question, teachers were asked to assign subjects to social status groups which corresponded with classifications derived from peer nomination data. This question was important to examine because the practice of asking children to make negative sociometric choices has been challenged on ethical grounds. For example, despite the unique information that negative peer nominations provide about social risk status, some have questioned whether asking children to make negative choices might further impair the social reputations of rejected peers, or even implicitly sanction the process of ostracizing certain classmates (Asher \& Hymel, 1981). Although this controversy is far from settled, if teachers agree closely with peers concerning the identification of rejected children, they may be preferable informants (not only from an ethical standpoint, but in terms of cost effectiveness as well).

3. Finally, what is the relative stability of behavioral vs. sociometric measures in the classification of at-risk preschoolers? In previous studies, measures of aggressive and disruptive behavior have been found to correlate with measures of negative peer status in preschool-age children (Millich, Landau, Kilby, \& Whitten, 1982; Olson, 1990; Olson \& Lifgren, 1988; Rubin \& Clark, 1983). Although problems of conduct and peer rejection are not isomorphic, they are clearly interrelated and predictive of continuing problems of social adaptation. Thus, we examined these measures in relation to their comparative stability over the course of the preschool year. In order to address this issue, the "peer diagnostician" technique of Milich et al. (1982) was employed, whereby children are asked to nominate classmates who show high rates of aggression, disruptiveness, and impulsivity. This technique has proven to be both reliable and valid with preschool-age children 
(Milich et al., 1982); however, the stability of these measures has not been examined.

\section{METHOD}

\section{Subjects}

Subjects were 53 boys $4-5$ years old $(M=4$ years 6 months; range $=4-0$ to 5-5) from low-income families. All boys were enrolled in Head Start preschool programs that extended from late September through midMay of the following year. The boys were drawn from eight Head Start classes (average class size $=11$ ) serving a total of 96 families. The racial composition of the classes was homogeneous (96\% white). Written parental consent and verbal child assent were obtained for all participants; no parent or child refused participation. Subjects were free of physical and mental disabilities.

\section{Procedures}

Overview. Teacher and peer assessments of children's social and behavioral status were conducted during the same time periods. The first assessment period occurred in the fall, at the end of the second month of preschool, and the second occurred in the spring, 1 month before classes ended.

Assessment of Peer Status. During the fall, children in each classroom (including girls) participated in individual peer sociometric interviews. After identifying self and classmates from a picture array, each child was asked to nominate two classmates s/he most liked to play with, then two classmates s/he least liked to play with (because of the relatively small number of raters in each class, two choices rather than the standard three were used). To obtain information about perceptions of behaviorally deviant peers, children were also asked to nominate two classmates who best fit each of the following behavioral descriptors (adapted from Millich et al., 1982): is mean; fights, hits, and punches a lot; runs around the room a lot; gets mad easily; can't sit still; and doesn't listen. Total scores on each sociometric variable were tallied for each boy in the study, then standardized to correct for small variations in class sizes. All peer sociometric procedures were repeated in the late spring $(n=52)$.

The following summary scores were obtained for each subject: number of negative nominations $(M=1.7, S D=1.7$ at time, $1, M=1.9, S D$ 
$=1.8$ at time 2$)$; number of positive nominations $(M=1.67, S D=1.20$ at time $1, M=1.84, S D=1.53$ at time 2 ); number of aggression nominations, created by summing the items mean, fights, and gets mad $(M=4.27$, $S D=3.40$ at time $1, M=5.35, S D=3.94$ at time 2 ); and number of hyperactivity nominations, created by summing the items runs around, can't sit still, and doesn't listen $(M=5.23, S D=3.09$ at time $1, M=5.21, S D$ $=4.08$ at time 2 ).

Teacher Rating and Nomination Instruments. During the fall, teachers completed the Conners Teacher Questionnaire (Goyette, Conners, \& Ulrich, 1978). This version of the questionnaire consisted of thirty-three 4point scales, on which the presence of specific behavior problems was rated $(1=$ not at all a problem; $4=$ very much a problem $)$. The two major questionnaire scales were Conduct Problems (acts impudent; temper outbursts; hypersensitive to criticism; sulks; mood changes quickly; aggressive: $M=$ $11.79, S D=4.07$ at time $1, M=11.06, S D=3.82$ at time 2 ) and Hyperactivity (restless; makes inappropriate noises; disturbs other children; constantly on the go; impulsive and excitable; excessive demands for teacher's attention: $M=11.81, S D=5.05$ at time $1, M=11.58, S D=5.51$ at time 2). A second assessment technique was developed for the purposes of this study. Teachers were asked to assign each child to one of the following sociometric categories: very popular with peers; average popularity with peers; mostly ignored by peers; and mostly disliked by peers. All teacher rating and nomination procedures were repeated during the final month of preschool.

Group Classification. The method of Coie et al. (1982) was used to assign children to sociometric groups. Two summary scores were derived from standardized frequencies of positive and negative nominations: social preference or SP (like-dislike) and social impact or SI (like + dislike). Sociometric groups were defined as follows $(\mathrm{L}=$ like and $\mathrm{D}=$ dislike): popular ( $\mathrm{SP}>1.0, \mathrm{~L}>0, \mathrm{D}<0)$; rejected $(\mathrm{SP}<-1.0, \mathrm{~L}<0, \mathrm{D}>0)$; neglected (SI $<-1.0, \mathrm{~L}<0, \mathrm{D}<0$ ); controversial $(\mathrm{SI}>1.0, \mathrm{~L}>0, \mathrm{D}$ $>0$ ); average (SP and SI between -.5 and .5 ); and other (children whose scores did not fit the above criteria).

Peer nominations of behavioral deviance were summed to create total behavior problems scores $(M=6.8, S D=4.7$ at time $1, M=8.8, S D=$ 6.6 at time 2). Chronbach's alpha coefficients were .73 at time 1 and .82 at time 2 for the composite scales. Composite scores that were at least 1 standard deviation above the mean comprised the behavior problems group. Teachers' ratings of behavioral deviance were treated similarly: Children's scores on the Conduct Problems and Hyperactivity scales were summed and composited $(M=23.66, S D=8.56$ at time $1 ; M=22.50$, $S D=13.27$ at time 2). Total externalizing problems scores that exceeded 
Table I. Intercorrelations Between Measures of Social Rejection and Behavioral Deviance ${ }^{a}$

\begin{tabular}{|c|c|c|c|c|c|}
\hline & \multicolumn{3}{|c|}{ Peer scales } & \multicolumn{2}{|c|}{ Teacher scales } \\
\hline & $\begin{array}{c}\text { Negative } \\
\text { nominations }\end{array}$ & Aggression & Hyperactivity & $\begin{array}{l}\text { Conduct } \\
\text { problems }\end{array}$ & Hyperactivity \\
\hline \multicolumn{6}{|l|}{ Peer scales } \\
\hline Negative nominations & & $.59^{b}$ & $.30^{c}$ & $.25^{c}$ & $.28^{c}$ \\
\hline Aggression & $.60^{b}$ & & $.38^{c}$ & $.32^{d}$ & $.45^{b}$ \\
\hline Hyperactivity & $.66^{b}$ & $.86^{b}$ & & $.36^{d}$ & $.51^{b}$ \\
\hline \multicolumn{6}{|l|}{ Teacher scales } \\
\hline Conduct problems & $.42^{d}$ & $.46^{b}$ & $.44^{d}$ & & $.75^{b}$ \\
\hline Hyperactivity & $.35^{d}$ & $.44^{d}$ & $.58^{b}$ & $.83^{b}$ & \\
\hline
\end{tabular}

${ }^{a}$ Time 1 correlations above the diagonal; time 2 correlations below the diagonal.

${ }^{b} p<.001$.

$c_{p}<.05$.

$a_{p}<.01$.

1 standard deviation above the mean comprised the behavior problems group. Alpha coefficients for the composite scales were .94 at time 1 and .93 at time 2 .

\section{RESULTS}

\section{Intercorrelations Between Peer and Teacher Scales}

Intercorrelations between peer and teacher measures of negative sociometric status and behavioral deviance are shown in Table I. Correlations between time 1 measures are shown above the diagonal, with correlations between time 2 measures shown below. As expected, there were significant correlations between peers' dislike nominations and nominations of conduct and impulsivity problems. Dislike scores were moderately highly correlated with nominations of aggressive problem behavior at both assessment points, and with nominations of impulsive behavior at time 2. Finally, teachers' ratings of externalizing problem behavior were modestly correlated with peers' dislike nominations, and moderately correlated with peer nominations of aggression and impulsivity.

\section{Stability of Teacher and Peer Scales}

Stability coefficients for measures of behavioral deviance and negative social status are shown in Table II. All coefficients were highly significant. The negative peer nomination scale showed moderate stability over a 6- 
Table II. Stability of Peer and Teacher Measures from

Fall to Spring

\begin{tabular}{ll}
\hline Peer scales & \\
Negative nominations & $.44^{a}$ \\
Aggression & $.64^{b}$ \\
Hyperactivity & $.56^{b}$ \\
Total (aggression + hyperactivity) & $.68^{b}$ \\
Teacher scales & \\
Conduct problems & $.70^{b}$ \\
Hyperactivity & $.80^{b}$ \\
Total (conduct problems + hyperactivity) & $.80^{b}$ \\
\hline$a_{p}<.01$. & \\
$b_{p}<.001$. &
\end{tabular}

month time span, whereas both peer and teacher measures of behavioral deviance showed relatively high stability.

\section{Peer vs. Teacher Classifications of Rejected Status}

At time 1,12 boys ( $22 \%$ of sample) were classified as rejected on the basis of peer nominations. Other sociometric groupings were: neglected, 9 boys (17\%); average, 24 boys (45\%); popular, 6 boys (11\%); and controversial, 2 boys (3\%), Teachers classified 4 boys as mostly disliked by peers at time 1 , and teachers and peers did not agree on assignment of specific children to the rejected category: Only two boys were classified as such by both teachers and peers, percentage of agreement $=.14$ ( $n$ of agreements $/ n$ of agreements $+n$ of disagreements).

At time 2, 10 boys (19\%) were classified as rejected on the basis of peer nominations, whereas $9(17 \%)$ were classified as neglected, $19(36 \%)$ as average, $10(19 \%)$ as popular, and $4(7 \%)$ as controversial. Teachers classified 5 boys as mostly disliked, but only agreed with peers on two specific choices (percentage of agreement $=.15$ ). ${ }^{3}$

Next, the stability of peer and teacher classifications of rejected boys was examined. Half $(50 \%$; kappa $=.47)$ of the boys initially classified by peers as rejected retained their rejected status at time 2. All (100\%; kappa $=.88$ ) of the boys identified by teachers as mostly disliked were classified as such at the end of the year. ${ }^{4}$

\footnotetext{
${ }^{3}$ Peer nominations were also analyzed for the entire sample of boys and girls $(N=88)$ by Brodfeld (1989). At time 1, only 2 girls met criteria for rejected status, and at time 2, 3 girls were classified as rejected. Thus, although both boys and girls contributed nominations, the vast majority of peer rejected children were boys.

${ }^{4}$ Of the 6 boys who were rejected in the fall but did not remain so over time, 4 were classified as average and 2 as neglected at time 2 . Of the 4 boys who became rejected across the year, 3 were classified as average and one as neglected at time 1.
} 


\section{Peer vs. Teacher Classifications of Behavioral Deviance}

At time 1,10 boys were identified by peers and 10 by teachers as having significant behavior problems. Percentage of agreement between teachers and peers regarding specific boys was .66 , kappa $=.75$ (8 agreements, 4 disagreements).

At time 2, 12 boys were identified by peers and 10 by teachers as having behavior problems. Percentage of agreement between teachers and peers on assignment of specific children to this category was .61, kappa $=$ .75 (8 agreements, 5 disagreements).

All 10 boys $(100 \%$; kappa $=.90)$ who were initially classified as aggressive/disruptive on the basis of peer nominations retained this status at time 2 . Similarly, of the 10 boys initially identified by teachers as having significant behavior problems, $9(90 \%$; kappa $=.82)$ were classified as behaviorally deviant at time 2 .

Finally, there was a moderate degree of overlap between children classified as rejected and behaviorally deviant. At time 1, $42 \%$ of boys classified as rejected were also classified by peers as behaviorally deviant; at time $2,50 \%$ of the rejected boys were also classified as having significant behavior problems. Although the small sample sizes greatly limit our ability to research this question, children's behavioral status at time 1 did not appear to be an obvious indicator of continuing risk of peer rejection. Of the 6 boys who retained their rejected status, $50 \%$ were designated as behaviorally deviant at time 1 . Of those whose rejected status was not retained throughout the year, $33 \%$ were designated as behaviorally deviant at time 1. This issue merits further examination with larger sample sizes.

\section{DISCUSSION}

This study focused on the assessment of negative peer status and behavioral deviance in preschool boys. Because little is known about the risk potential of negative social status in preschoolers, a short-term longitudinal design was used to examine the stability of social rejection in this population. The traditional measure of negative sociometric status, negative peer nominations, had significant but moderate stability over a 5 -month interval. Half of the boys designated as rejected on the basis of peer nominations remained so throughout the year. This finding extends prior research by showing that peer-rejected children can be identified at very young ages, and that a significant proportion of them retain this status over the course of the preschool year. However, the moderate stability coefficient also indicates a need for caution in categorizing the 
risk potential of individual preschoolers, especially from the standpoint of early intervention.

Agreement between teachers and peers on identification of rejected children was also examined, due to the recent controversy over the use of negative peer nominations. Teachers classified very few children as mostly disliked by peers and had extremely poor agreement with the children themselves on the selection of rejected individuals. The low number of selections suggests that teachers may have felt reluctant to characterize children in this way, perhaps because of the negatively value-laden nature of the category. Although teachers were remarkably stable in their designations of disliked children, it is clear that their nominations did not substitute for peer nomination data.

Finally, measures of behavioral deviance (aggression; disruptiveness; impulsivity) were assessed by teachers and peers, and compared with measures of peer rejection. As expected, negative peer nominations were significantly correlated with peer and teacher measures of externalizing type behavior problems; consistent with the findings of Milich et al. (1982), peer nominations of aggressive behavior (who is mean to other children? who fights a lot?) were more robustly correlated with dislike scores than nominations of impulsive behavior. By contrast with measures of negative status, peers and teachers had good agreement concerning the identification of specific children with behavior problems, providing additional support for the validity of Milich et al.'s "peer diagnostician" assessment technique. Perhaps the most striking finding, though, was the high stability of both teacher and peer classifications of aggressive/disruptive children. All boys identified by peers as highly deviant retained this status at the end of the year; the stability of the teacher evaluations was nearly as high.

Thus, as indicators of continuing risk of maladjustment in young children, measures of behavioral deviance were superior to those of negative sociometric status, at least over the course of the preschool year. These findings suggest that sociometric measures should not be used alone to designate risk groups of young children, but rather in combination with measures of behavioral deviance. Why were peer perceptions of children with behavior problems more stable than perceptions of disliked peers? Perhaps because the behavioral categories were less subjective than categories of liking and disliking. It should be noted, though, that the behavior problem nominations were summed across multiple items, whereas the negative nomination score was based upon a single prompt. This difference would favor the reliability of the behavioral measure on psychometric grounds alone, irrespective of item content.

In further research, preschool-age measures of peer rejection and behavioral deviance should be evaluated across a longer time span than that 
employed in the current study. For example, how well do preschool peer perceptions of deviance and dislikability predict children's social adjustment in the school-age years, and is one measure superior to the other as an index of long-term risk?

Finally, our relatively small, sex-specific sample, combined with the fact that all children were from low-income families, suggests a need for caution in generalizing these findings to other populations. However, in demonstrating that preschoolers can be valuable informants about the social maladaptation of peers, these findings have promise for further research on early social risk factors and early intervention.

\section{REFERENCES}

Asher, S. R., \& Dodge, K. A. (1986). Identifying children who are rejected by their peers. Developmental Psychology, 22, 444-449.

Asher, S. R., \& Hymel, S. (1981). Children's social competence in peer relations: Sociometric and behavioral assessment. In J. D. Wine and M. D. Smye (Eds.), Social competence (pp. 125-157). New York: Guilford Press.

Brodfeld, P. (1989). Preschoolers' peer relationships: Social status groups and reciprocal friendships. Unpublished manuscript, University of Michigan, Department of Psychology, Ann Arbor.

Coie, J. D., \& Dodge, K. A. (1983). Continuities and changes in children's social status: A five-year longitudinal study. Merrill-Palmer Quarterly, 29, 261-282.

Coie, J. D., Dodge, K. A., \& Copotelli, H. (1982). Dimensions and types of social status: A cross-age perspective. Developmental Psychology, 18, 557-570.

Crowther, J. H., Bond, L. A., \& Rolf, J. E. (1981). The incidence, prevalence, and severity of behavior disorders among preschool-aged children in daycare. Journal of Abnormal Child Psychology, 9, 23-42.

Dodge, K. A. (1983). Behavioral antecedents of peer social status. Child Development, 54, 1386-1399.

Goldman, J. A., Corsini, D. A., \& DeUrioste, R. (1980). Implications of positive and negative sociometric status for assessing the social competence of young children. Joumal of Applied Developmental Psychology, 1, 209-220.

Goyette, C. H., Conners, C. K., \& Ulrich, R. F. (1978). Normative data on revised parent and teacher rating scales. Journal of Abnormal Child Psychology, 6, 221-236.

Loeber, R. (1982). The stability of antisocial and delinquent behavior: A review. Child Development, 53, 1431-1446.

McCandless, B. R., \& Marshall, H. R. (1957). A picture sociometric technique for preschool children and its relation to teacher judgements of friendship. Child Development, 28, 139 147.

Milich, R., Landau, S., Kilby, G., \& Whitten, P. (1982). Preschool peer perceptions of the behavior of hyperactive and aggressive children. Journal of Abnormal Child Psychology, 10, 497-510.

Newcomb, A. F., \& Bukowski, W. M. (1983). Social impact and social preference as determinants of children's peer group status. Developmental Psychology, 19, 856-867.

Olson, S. L. (1990). Development of conduct problems and peer rejection in preschool children: A social systems analysis. Manuscript submitted for publication.

Olson, S. L., \& Lifgren, K. (1988). Concurrent and longitudinal correlates of preschool peer sociometrics: Comparing rating scale and nomination measures. Journal of Applied Developmental Psychology, 9, 409-420. 
Parker, J. G., \& Asher, S. R. (1987). Peer relations and later personal adjustment: Are lowaccepted children at risk? Psychological Bulletin, 102, 357-389.

Rubin, K. A., \& Clark, M. L. (1983). Preschool teachers' ratings of behavioral problems: Observational, sociometric, and social-cognitive correlates. Journal of Abnormal Child Psychology, 11, 273-286.

Rutter, M., \& Garmezy, N. (1983). Developmental psychopathology. In E. M. Hetherington (Ed.), Carmichael's manual of child psychology (Vol. 4): Social and personality development (pp. 775-912). New York: Wiley.

Spivack, G., Marcus, J., \& Swift, M. (1986). Early classroom behaviors and later misconduct. Developmental Psychology, 22, 124-131. 